\title{
miR-4458 directly targets IGF1R to inhibit cell proliferation and promote apoptosis in hemangioma
}

\author{
MAOSONG WU ${ }^{1}$, YONGSHENG TANG ${ }^{1}$, GANG HU $^{1}$, CHUNJIAN YANG $^{1}$, \\ KAICHUANG YE ${ }^{2}$ and XIANLUO LIU ${ }^{1}$ \\ ${ }^{1}$ Department of General Surgery, The Second People's Hospital of Hefei, Hefei, \\ Anhui 230011; ${ }^{2}$ Department of Vascular Surgery, Ninth People's Hospital, \\ Shanghai Jiao Tong University School of Medicine, Shanghai 230011, P.R. China
}

Received December 3, 2018; Accepted October 11, 2019

DOI: $10.3892 /$ etm.2020.8546

\begin{abstract}
Hemangiomas (HAs) are benign neoplasms of the vasculature. MicroRNA-4458 (miR-4458) has been reported to function as a tumor suppressor in multiple malignancies, but its biological function in HAs remains unknown. In the present study, the potential role of miR-4458 in HA-derived endothelial cells (HDECs) was investigated. Firstly, reverse-transcription-quantitative PCR analysis was used to confirm the expression of miR-4458 in HDECs following transfection with miR-4458 mimics or inhibitor. Subsequently, MTT and EdU assays were performed and subsequently determined that miR-4458 overexpression significantly inhibited proliferation, and knockdown promoted cell proliferation in HDECs. Flow cytometry analysis revealed that miR-4458 overexpression induced cell cycle arrest, whereas knockdown reversed G0/G1 phase arrest and apoptosis. Furthermore, insulin-like growth factor 1 receptor (IGF1R) was identified as a target of miR-4458. IGF1R knockdown enhanced the effects of miR-4458 on cell proliferation, cell cycle G0/G1 phase arrest and apoptosis in HDECs. Taken together, the results revealed that miR-4458 targeting of IGF1R may serve as a novel therapeutic strategy for treating patients with HAs.
\end{abstract}

\section{Introduction}

Hemangiomas (HAs) remains the most common benign vascular tumors among infants, with an annual frequency of 5-10\% (1). Its appearance is similar to infantile hemangiomas and congenital hemangiomas, but their clinical presentations are considered to be different (1). The life cycle of HA consists of three stages: Proliferation, quiescence and involution (2). As stem/progenitor

Correspondence to: Dr Xianluo Liu, Department of General Surgery, The Second People's Hospital of Hefei, 246 Peace Road, Yaohai, Hefei, Anhui 230011, P.R. China

E-mail: xianl_liu75@163.com

Key words: hemangioma, microRNA-4458, insulin-like growth factor 1 receptor, proliferation cells, angiogenesis and pre-existing vessels are sufficient to induce vasculogenesis, HA proliferation is likely to occur (3). HA-derived endothelial cells (HDECs), progenitor/stem cells and perivascular cells are three well-characterized cells isolated from Has $(4,5)$. However, the mechanisms underlying the development and progression of HA are not yet fully understood.

MicroRNAs (miRNAs/miRs) are short regulatory RNAs usually consisting of $\sim 22$ nucleotides (6). These genes function as important regulators that mediate mRNA degradation or protein-coding silencing in a sequence-dependent manner (7). miRNAs serve a critical role in cancer cell growth, apoptosis, epithelial-mesenchymal transition, therapy response and clinical outcome (8). Several miRNAs, including miR-126 (9), miR-424 (10), miR-143 (11) and let-7 (12) have been detected in resected tumor tissues or cell lines, and have been demonstrated to tightly regulate the development of HA. Previous reports have revealed frequent miR-4458 downregulation in lung cancer (13), hepatocellular carcinoma (HCC) (14) and colon cancer (15). miR-4458 acts as a tumor suppressor and decreases the proliferation of lung cancer cells (13). It also functions as a potential predictor of HCC (14) and guides glycolysis and lactate production in colon cancer cells (15). However, the role of miR-4458 in HA is yet to be elucidated.

Receptor tyrosine kinase insulin-like growth factor 1 receptor (IGF1R), located on 15q26.3, is expressed ubiquitously on cell surfaces and the binding of its ligands (IGF1, IGF2 and insulin) triggers the tyrosine kinase activity of the receptor $(16,17)$. Abnormalities of the IGF1R signaling pathway are associated with growth, progression and disorders of metabolism in a range of different types of cancer $(18,19)$. Hyperexpression of the IGF1R gene is frequently observed in breast cancer (18), penile cancer (19) and epithelial ovarian cancer (20). Numerous studies have demonstrated that IGF1R induces proliferation, survival, cell cycle progression and a series of malignant behaviors in cancer cells (20-22). A previous study provided novel insight into the biological function of another IGF receptor, IGF2R, in HA (23). Silencing of IGFR2 abrogated the proliferation of HDECs and promoted apoptosis in vitro and in vivo (23). miR-4458 has been implicated in IGF1R signaling, which regulates the development of lumbar disc degeneration (24). Therefore, these results may suggest a potential implication for IGF1R in the development of HA. 
In the present study, the cellular functions of miR-4458 and one of its key targets, IGF1R, were determined. The potential molecular mechanisms of action were validated in vitro, thus, highlighting the potential of targeting the miR-4458/IGF1R axis in patients with HAs.

\section{Materials and methods}

Cell culture and transfection. Primary HDECs derived from proliferating-phase HA tumors were purchased from the Cell Bank of Type Culture Collection of the Chinese Academy of Sciences. Human umbilical vein endothelial cells (HUVECs) were purchased from the American Type Culture Collection. The cell lines were cultured in DMEM (Thermo Fisher Scientific Inc.) with $10 \%$ heat-inactivated FBS (Thermo Fisher Scientific Inc.) in a humidified atmosphere containing $5 \% \mathrm{CO}_{2}$ at $37^{\circ} \mathrm{C}$.

The miR-4458 mimics, miR-4458 inhibitor and miR-negative control (NC) were purchased from Guangzhou RiboBio Co., Ltd. Small interfering (si)RNA targeting IGF1R (si-IGF1R) and si-NC were synthesized by Shanghai GenePharma Co., Ltd. The experimental design was adapted from previously described literature $(11,25,26)$. HDECs were seeded in 24-well plates at a density of $5 \times 10^{4}$ cells per well, and when the cells had reached $80 \%$ confluency, they were transfected with $50 \mathrm{nM}$ of mimics or inhibitor, or $10 \mu \mathrm{g}$ of the si-IFG1R or si-NC plasmids for $48 \mathrm{~h}$ using Lipofectamine ${ }^{\circledR} 2000$ reagent (Invitrogen; Thermo Fisher Scientific, Inc.) according to the manufacturer's protocol.

Reverse transcription-quantitative (RT-q)PCR. Total RNA was extracted from cells using TRIzol ${ }^{\circledR}$ reagent (Invitrogen; Thermo Fisher Scientific, Inc.) according to the manufacturer's protocol. To quantify miR-4458 expression, RT-qPCR was performed in triplicate on a 7300 Real-Time PCR system (Applied Biosystems; Thermo Fisher Scientific, Inc.) using a TaqMan microRNA Reverse Transcription kit (Thermo Fisher Scientific, Inc.) and TaqMan gene expression master mix (Thermo Fisher Scientific, Inc.). The temperature conditions for reverse transcription were as follows: $37^{\circ} \mathrm{C}$ for $15 \mathrm{~min}$ and $85^{\circ} \mathrm{C}$ for $5 \mathrm{sec}$. For the detection of IGF1R, RT-qPCR was performed using PrimeScript RT Master mix (Takara Bio, Inc.) and a QuantiNova SYBR Green PCR kit (Qiagen China Co., Ltd.) according to the manufacturer's protocol. The sequences of the primers used were as follows: miR-4458 forward, 5'-AGA GGTAGGTGTGGAAGAA-3' and reverse, 5'-GCGAGCACA GAATTAATACGAC-3; U6 forward, 5'-CTCGCTTCGGCA GCACA-3' and reverse, 5'-AACGCTTCACGAATTTGCG T-3'; IGF1R forward, 5'-TCGACATCCGCAACGACTATC-3' and reverse, 5'-TCGACATCCGCAACGACTATC-3'; GAPDH forward, 5'-ATCACCATCTTCCAGGAGCGA-3' and reverse, 5'-CCTTCTCCATGGTGGTGAAGAC-3'. The data were analyzed using the comparative Cq method $\left(2^{-\Delta \Delta C q}\right)(27)$. The expressions of miR-4458 and IGF1R were normalized to those of U6 small nuclear RNA and GAPDH, respectively.

Cell proliferation assay. A cell proliferation assay was performed using an MTT and 5-ethynyl-2'-deoxyuridine (EdU) incorporation assay. For the MTT assay, cells at a density of $5 \times 10^{3}$ cells/well were incubated in 96-well plates in triplicate and cultured at $37^{\circ} \mathrm{C}$ for five days. At the timepoints of $1,2,3,4$ and 5 days, cells were treated with $10 \mu 1$
MTT (0.5 mg/ml; Sigma-Aldrich; Merck KGaA) for $2 \mathrm{~h}$ at $37^{\circ} \mathrm{C}$, followed by incubation with $100 \mu \mathrm{l}$ of DMSO for $2 \mathrm{~h}$ at $37^{\circ} \mathrm{C}$. The absorbance was recorded at $595 \mathrm{~nm}$ using an enzyme immunoassay analyzer (Bio-Rad Laboratories, Inc.). For the EdU labeling assay, a Cell-Light EdU DNA cell kit (Guangzhou RiboBio Co., Ltd.) was used. Transfected cells were seeded into 96 -well plates $\left(1 \times 10^{4}\right.$ cells/well $)$ and cultured at $37^{\circ} \mathrm{C}$ for $48 \mathrm{~h}$. Subsequently, cells were washed twice with PBS and permeabilized using $0.5 \%$ Triton X-100 for $10 \mathrm{~min}$. Subsequently $50 \mathrm{mM}$ EdU solution was added to each well for $2 \mathrm{~h}$, and the cells were fixed and stained using 1x Apollo567 for $30 \mathrm{~min}$ in darkness at $37^{\circ} \mathrm{C}$. The nucleus was counterstained with DAPI (Sigma-Aldrich; Merck $\mathrm{KGaA}$ ) at $37^{\circ} \mathrm{C}$ for $30 \mathrm{~min}$. Stained cells were examined using a fluorescence microscope (magnification, x200; Nikon Corporation). The proportion of EdU-positive nuclei (red) to blue fluorescent nuclei was calculated by counting six microscopic fields randomly for each well in five separate experiments.

Analysis of cell cycle and apoptosis using flow cytometry. To detect cell cycle progression, transfected cells were collected, washed twice with cold PBS and fixed with $70 \%$ ethanol overnight at $4^{\circ} \mathrm{C}$. Subsequently, cells were washed with PBS twice and stained with $50 \mathrm{mg} / \mathrm{ml}$ propidium iodide (PI; Sigma-Aldrich; Merck KGaA) for $30 \mathrm{~min}$ at room temperature. The percentage of cells in the G0/G1, S and G2/M phase was determined using flow cytometry (BD Biosciences). For apoptosis analysis, transfected cells were trypsinized, washed with cold PBS and resuspended in fluorescence-activated cell-sorting (FACS) buffer containing 2\% FBS and treated with the FITC-Annexin V Apoptosis Detection kit with 7-AAD (BioLegend, Inc.) for $30 \mathrm{~min}$ at $4^{\circ} \mathrm{C}$. Early apoptosis (Annexin $\mathrm{V}^{+} / 7-\mathrm{AAD}^{-}$) and late apoptosis (Annexin $\mathrm{V}^{+} / 7-\mathrm{AAD}^{+}$) were analyzed using flow cytometry and Cell Quest software (version 5.1; BD Biosciences). Three separate experiments were performed for each sample.

Bioinformatics and luciferase reporter assay. Online miRNA target prediction algorithms, including PicTar4 (pictar. mdc-berlin.de), TargetScan (targetscan.org/vert_71/) and miRanda (microrna.org) were used to predict the potential target genes of miR-4458. For the luciferase reporter assay, a fragment of IGF1R 3' untranslated region (UTR) containing the putative binding site of miR-4458 was amplified and inserted into the luciferase reporter vector psiCHECK-2 (Promega Corporation) between the XhoI and NotI sites to construct wild-type IGF1R reporter vector (Wt IGF1R). The nucleotides which paired with miR-4458 were mutated by site-directed mutagenesis and also cloned into psiCHECK-2 vector to construct mutated IGF1R 3'UTR reporter vector (Mut IGF1R). HDECs were co-transfected with $20 \mu \mathrm{g}$ of Wt IGF1R or Mut IGF1R with $200 \mathrm{ng}$ of miR-4458 mimic or miR-NC using Lipofectamine ${ }^{\circledR} 2000$. After 48 h of transfection, luciferase activity was measured using the Dual-luciferase Reporter assay system (Promega Corporation) according to the manufacturer's instructions. Firefly luciferase activity was normalized to Renilla luciferase activity.

Western blotting. Total proteins were extracted from HDECs using a RIPA lysis (Beyotime Institute of Biotechnology) 

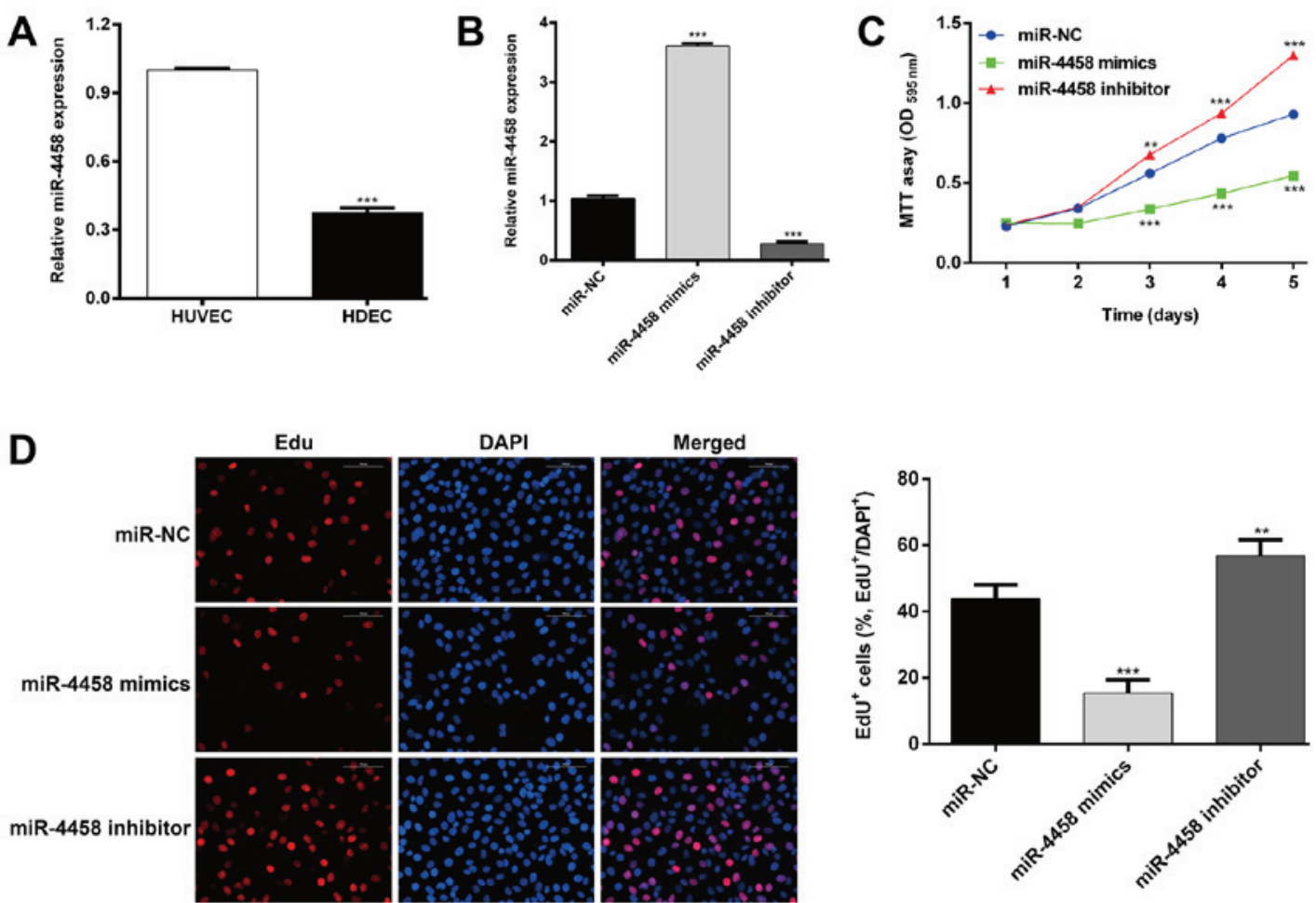

Figure 1. miR-4458 decreases cell proliferation in HDECs. (A) The mRNA expression of miR-4458 was determined in HDECs and HUVECs via reverse transcription-quantitative polymerase chain reaction. ${ }^{* * *} \mathrm{P}<0.001$ vs. HUVEC. (B) Relative expression of miR-4458 in HDECs transfected with miR-4458 mimics or an miR-4458 inhibitor. ${ }^{* * *} \mathrm{P}<0.001$ vs. miR-NC. (C) An MTT assay was performed to determine the effect of transfection on proliferation. ${ }^{* * *} \mathrm{P}<0.01$ and ${ }^{* * *} \mathrm{P}<0.001$ vs. miR-NC. (D) Representative images and statistical analysis of Edu-positive cells in HDECs following transfection with miR-4458 mimics or the miR-4458 inhibitor respectively (magnification, $\mathrm{x} 200$ ). ${ }^{* *} \mathrm{P}<0.01$ and ${ }^{* * *} \mathrm{P}<0.001$ vs. miR-NC. miR, microRNA; HDEC, hemangioma derived epithelial cells; HUVEC, human umbilical vein endothelial cells; NC, negative control; OD, optical density.

and quantified using a Pierce bicinchoninic acid protein assay kit (Thermo Fisher Scientific Inc.). Protein samples $(30 \mu \mathrm{g})$ were resolved using 12\% SDS-PAGE and transferred onto a PVDF membrane (EMD Millipore). The membrane was blocked with $5 \%$ skim milk powder for $1 \mathrm{~h}$ at room temperature and subsequently incubated with a primary antibody against IGF1R (cat. no. ab131476; 1:2,000; Abcam) or GAPDH (cat. no. 10494-1-AP; 1:500,000; ProteinTech Group, Inc.) overnight at $4^{\circ} \mathrm{C}$. Following incubation with the primary antibodies, membranes were incubated with the goat anti-rabbit immunoglobulin G (HRP) secondary antibody (cat. no. ab205718; 1:5,000; Abcam) at room temperature for $2 \mathrm{~h}$. After washing with PBS, protein bands were visualized using enhanced chemiluminescence reagent (GE Healthcare).

Statistical analysis. All quantitative data were expressed as the mean \pm standard deviation from three independent experiments. Differences between two groups were compared using a Student's $\mathrm{t}$-test and differences between three or more were analyzed using one-way ANOVA followed by post hoc Tukey's test. $\mathrm{P}<0.05$ was considered to indicate a statistically significant difference.

\section{Results}

miR-4458 significantly decreases cell proliferation in HDECs. To determine the biological role of $\mathrm{miR}-4458$ in HAs, the expression of miR-4458 in HDECs and HUVECs was determined. As presented in Fig. 1A, the expression of miR-4458 was significantly lower in HDECs compared with HUVECs $(\mathrm{P}<0.001)$.
HDECs were subsequently transfected with miR-4458 mimics or an inhibitor to upregulate or downregulate the expression of miR-4458, respectively. The efficiency of transfection was determined using RT-qPCR (Fig. 1B; P<0.001). The effects of miR-4458 on the cell proliferation of HDECs was then determined. As presented in Fig. 1C, MTT assay results revealed that cell growth rate was significantly decreased in cells transfected with miR-4458 mimics ( $\mathrm{P}<0.001$ after 3 days), and enhanced in cells transfected with miR-4458 inhibitors $(\mathrm{P}<0.01$ after 3 days) when compared with cells transfected with miR-NC. The EdU incorporation assay (Fig. 1D) demonstrated that the percentage of EdU-positive cells was significantly reduced in cells transfected with miR-4458 mimics $(\mathrm{P}<0.001)$ compared with cells transfected with miR-NC. Transfection with of miR-4458 inhibitor significantly increased the percentage of EdU-positive cells compared with miR-NC treated cells $(\mathrm{P}<0.01)$. These data suggested that miR-4458 may be a negative regulator of proliferation in HDEC.

miR-4458 induces cell cycle arrest and apoptosis in HDECs. The effects of miR-4458 on HDECs cell cycle distribution and apoptosis were determined. As presented in Fig. 2A, the percentage of cells in G0/G1 were significantly increased following transfection miR-4458 mimics $(\mathrm{P}<0.01)$ and decreased in cells transfected with the miR-4458 inhibitor $(\mathrm{P}<0.001)$ when compared with miR-NC treated cells. Similarly, miR-4458 overexpression significantly reduced the percentage of cells in $\mathrm{G} 2 / \mathrm{M}$ $(\mathrm{P}<0.01)$ and miR-4458 knockdown increased the percentage of cells at $\mathrm{S}$ phase $(\mathrm{P}<0.001)$ compared with cells transfected with 
A
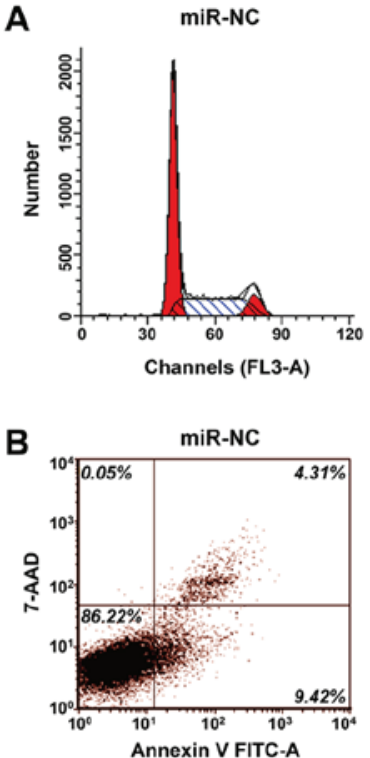

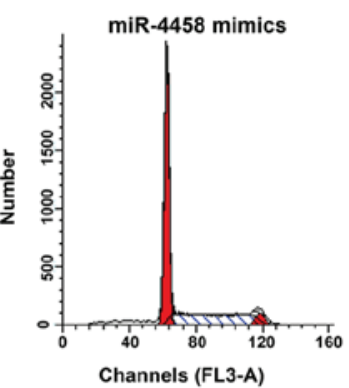

Channels (FL3-A)

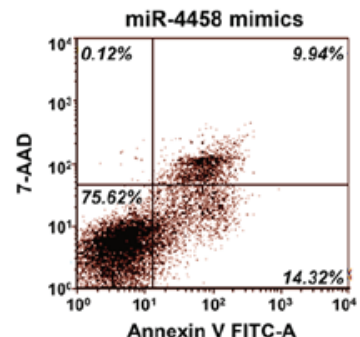

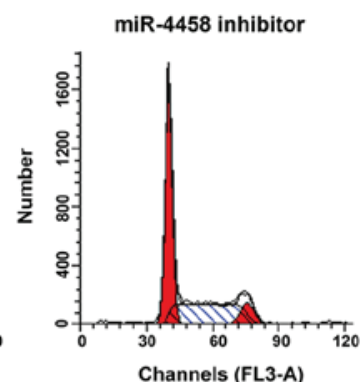
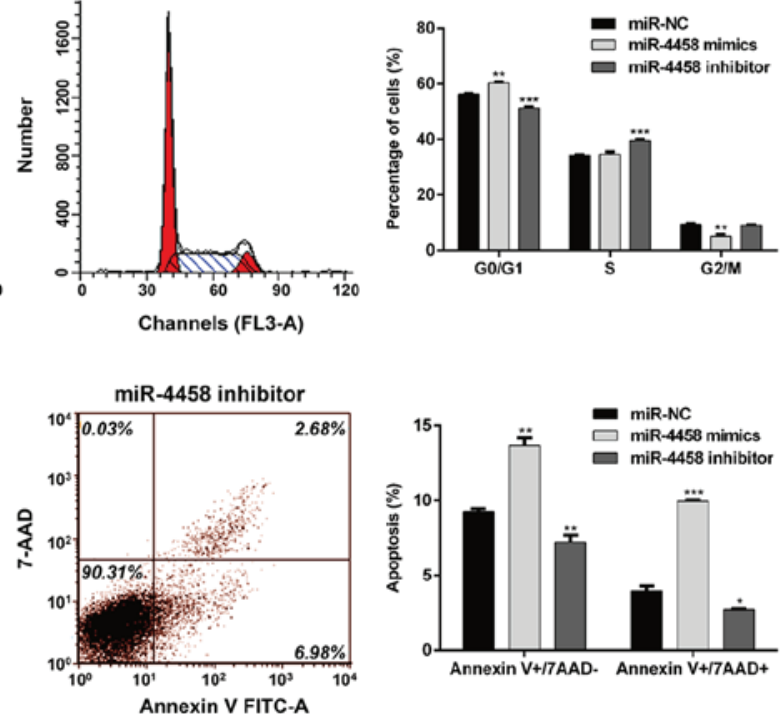

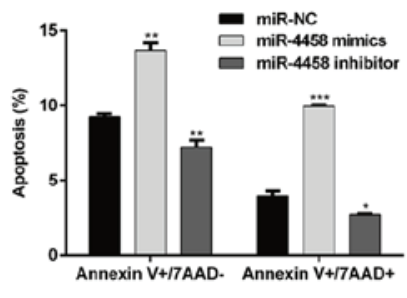

Figure 2. miR-4458 arrested HDECs at G0/G1 phase and promoted apoptosis. (A) Flow cytometry analysis of HDEC cell cycle distribution transfected with miR-4458 mimics, an miR-4458 inhibitor or an miR-NC. Representative histograms of cell cycle distribution are presented along with the quantification of cell cycle distribution from three independent experiments. ${ }^{* *} \mathrm{P}<0.01$ and ${ }^{* * *} \mathrm{P}<0.001$ vs. miR-NC. (B) Apoptosis was analyzed via Annexin-V/7-AAD staining. Representative dot plots of apoptosis flow cytometry analysis are presented, along with the quantification of apoptotic cells from three independent experiments. ${ }^{*} \mathrm{P}<0.05,{ }^{* *} \mathrm{P}<0.01$ and ${ }^{* * *} \mathrm{P}<0.001$ vs. miR-NC. miR, microRNA; HDEC, hemangioma derived epithelial cells; NC, negative control; 7-AAD, 7-Aminoactinomyosin D; FITC, fluorescein isothiocyanate.

A

Position of 99-105 of IGF1R

3'UTR Wt 5'...UUCACAAGCCUCCUGUACCUCAG...3' \|\|$\| \mid$

hsa-miR-4458 3'

3'UTR Mut 5'...UUCACAAGCCUCCUGUGAAGAAG...3'
B

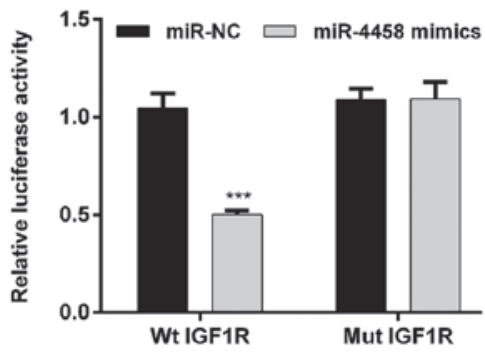

E

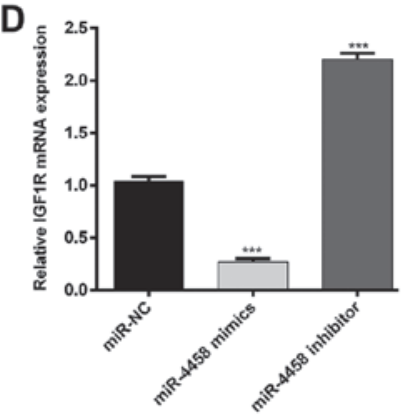

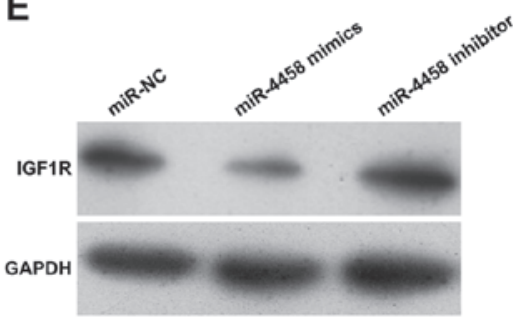

Figure 3. IGF1R is a target gene of miR-4458 in HDECs. (A) miR-4458 binding sites in the 3'-UTR of IGF1R mRNA were predicted. IGF1R mutations were constructed by mutating the base pairing site between miR-4458 and its target in the seed regions. (B) HDECs were co-transfected with miR-4458 mimics or miR-NCs, and Mut or Wt IGF1R 3'-UTR-luciferase reporters. Luciferase activity of the reporter genes containing either Wt IGF1R or Mut 3'-UTRs was determined after $48 \mathrm{~h}$. ${ }^{* * * *} \mathrm{P}<0.001$ vs. miR-NC. (C) RT-qPCR was performed to determine the expression of miR-4458 in HUVEC and HDEC cells. ${ }^{* * *} \mathrm{P}<0.001 \mathrm{vs}$. miR-NC. (D) RT-qPCR and (E) western blotting results of IGF1R expression in HDECs following transfection with miR-4458 mimics, inhibitor or miR-NC are presented. ${ }^{* * * * *} \mathrm{P}<0.001$ vs. miR-NC. IGF1R, insulin-like growth factor 1 receptor; miR, microRNA; HDEC, hemangioma derived epithelial cells; UTR, untranslated region; $\mathrm{NC}$, negative control; reverse transcription-quantitative PCR; Mut, mutant; Wt, wild-type; RT-qPCR, reverse transcription-quantitative polymerase chain reaction.

miR-NC. These results suggested that miR-4458 may induce cell cycle G0/G1 phase arrest in HDECs. In addition, flow cytometry analysis further demonstrated that miR-4458 overexpression promoted cell early apoptosis $(\mathrm{P}<0.01 ; 7 \mathrm{AAD})$ and late apoptosis $\left(\mathrm{P}<0.001 ; 7 \mathrm{ADD}^{+}\right)$, and the percentage of cells in both early $(\mathrm{P}<0.01)$ and late $(\mathrm{P}<0.05)$ was significantly reduced in cells transfected with the miR-4458 inhibitors in HDECs compared with cells transfected with miR-NC (Fig. 2B).

miR-4458 directly targets IGFIR in HDECs. To dissect the molecular mechanism by which miR-4498 regulates cell proliferation, cell cycle and apoptosis, bioinformatics analysis was 

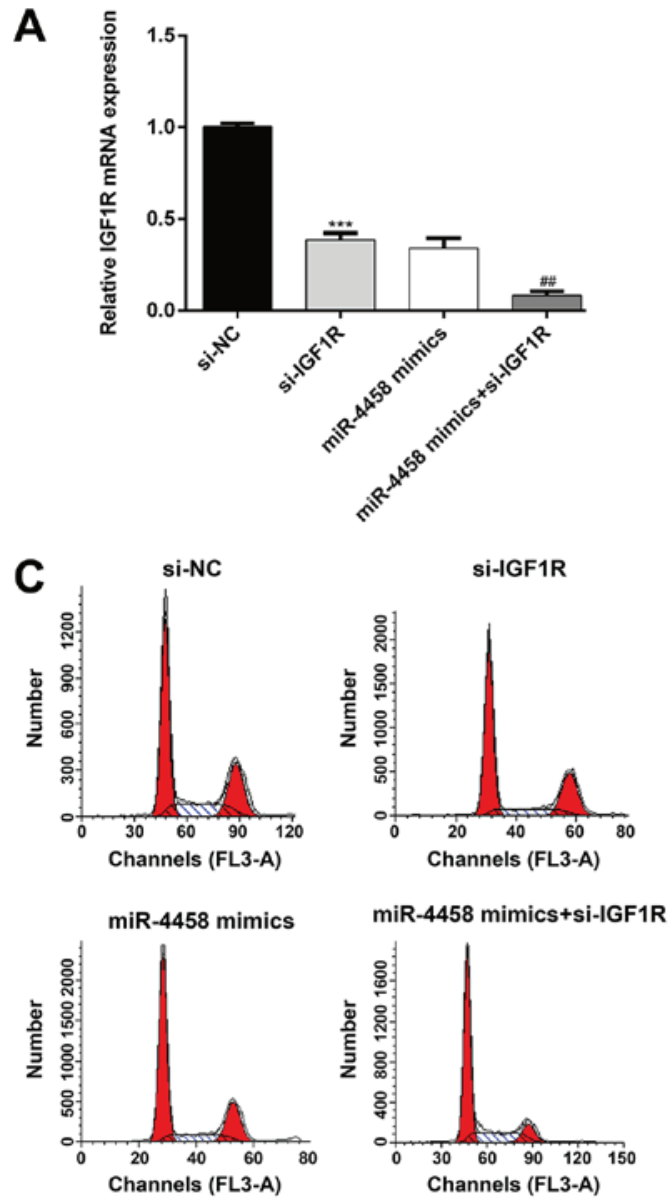

D

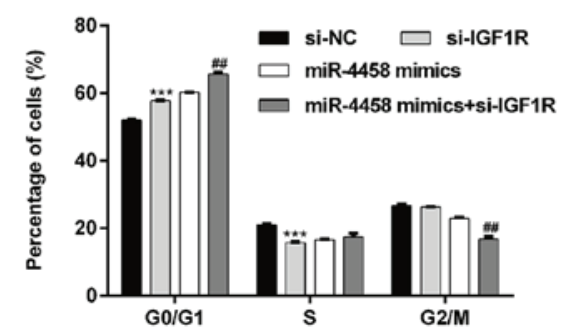

B

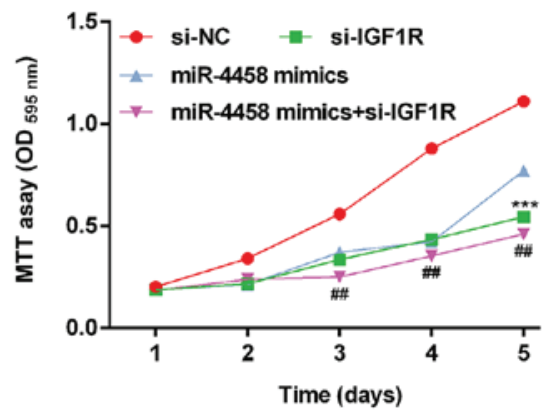

E
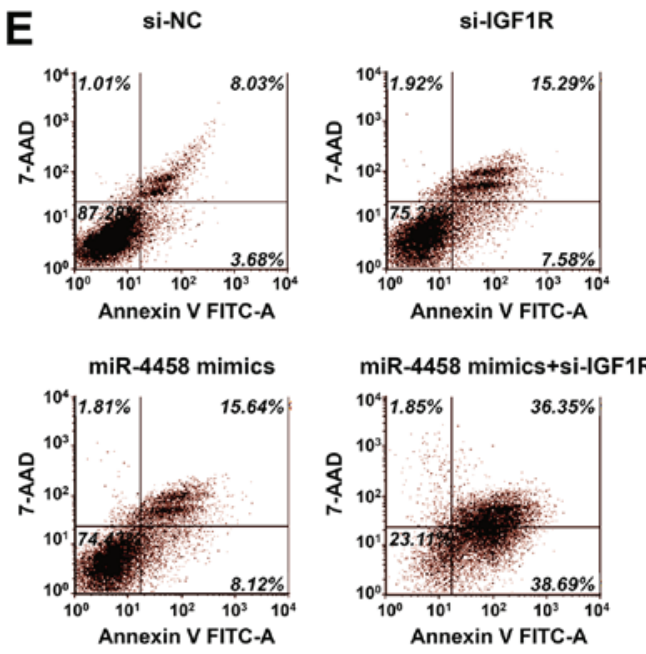

$\mathbf{F}$

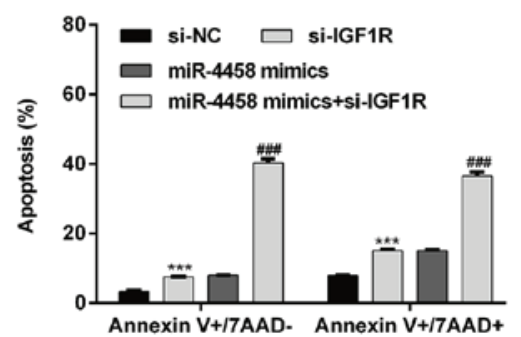

Figure 4. IGF1R regulates miR-4458-mediated cell proliferation, cell cycle progression and apoptosis. HDECs were transfected with si-IGF1R, miR-4458 mimics or miR-4458 mimics + si-IGF1R plasmid. (A) Reverse transcription-quantitative polymerase chain reaction was performed to determine the expression of miR-4458. ${ }^{* * * *} \mathrm{P}<0.001$ vs. si-NC; ${ }^{\# \#} \mathrm{P}<0.01$ vs. miR-4458 mimics; (B) Cell proliferation was determined using an MTT assay. ${ }^{* * *} \mathrm{P}<0.001 \mathrm{vs}$. si-NC; ${ }^{\# \#} \mathrm{P}<0.01$ vs. miR-4458 mimics. (C) Cell cycle distribution was determined using flow cytometry and propidium iodide staining and was quantified in (D). ${ }^{* * *} \mathrm{P}<0.001 \mathrm{vs}$. si-NC; ${ }^{\# \#} \mathrm{P}<0.01$ vs. miR-4458 mimics. (E) Apoptosis was determined using flow cytometry with Annexin V-FITC/7-AAD double staining and is quantified in $(\mathrm{F}){ }^{* * *} \mathrm{P}<0.001$ vs. si-NC; ${ }^{\# \# \#} \mathrm{P}<0.001$ vs. miR-4458 mimics. IGF1R, insulin-like growth factor 1 receptor; miR, microRNA; HDEC, hemangioma derived epithelial cells; si, small interfering; PI, propidium iodide; 7-AAD, 7-Aminoactinomyosin D; FITC, fluorescein isothiocyanate; NC, negative control.

performed to predict the target gene of miR-4458. Among these predicted genes, IGF1R was considered to be a potential target gene of miR-4458. The fragment of IGF1R 3' UTR containing the putative binding site of miR-4458 is presented in Fig. 3A. A dual-luciferase assay was performed to confirm whether IGF1R was a target gene of miR-4458. The results revealed that when the reporter vector containing the Wt IGF1R was transfected with miR-4458 mimics, the luciferase expression was significantly decreased when compared with the miR-NC (Fig. 3B; P<0.001), whereas mutation of the target region completely abolished this observation. Therefore, the expression of IGF1R in HDECs was determined and it was demonstrated that IGF1R mRNA expression was significantly higher in HDECs compared with HUVECs (Fig. 3C; P<0.001). RT-qPCR analysis (Fig. 3D; P<0.001) and western blotting analyses (Fig. 3E) further demonstrated that miR-4458 mimics decreased the expression of IGF1R, whereas the miR-4458 inhibitor increased its expression in HDECs. These results indicated that miR-4458 may negatively regulate the expression of IGF1R by directly targeting its 3'-UTR in HDECs.

IGFIR regulates miR-4458-mediated cell proliferation, cell cycle arrest and apoptosis. Since IGF1R was negatively regulated by miR-4458, it was speculated that miR-4458 also regulated cell proliferation, cell cycle progression and apoptosis by targeting IGF1R. To validate this hypothesis, HDECs were transfected with si-IGF1R, miR-4458 mimics or co-transfected with si-IGF1R and miR-4458 mimics, respectively. As shown in Fig. 4A, the expression of IGF1R was significantly decreased 
after si-IGF1R transfection when compared with si-NC transfection, and further notably decreased after co-transfection with miR-4458 mimics + si-IGF1R when compared with miR-4458 mimics transfection alone. As presented in Fig. 4B, IGF1R knockdown significantly decreased cell proliferation $(\mathrm{P}<0.001)$ when compared with si-NC transfection. IGF1R knockdown also enhanced the inhibitory effects of miR-4458 on cell proliferation in HDECs $(\mathrm{P}<0.01)$ when compared with miR-4458 mimics transfection alone. Furthermore, flow cytometry analysis revealed that IGF1R knockdown induced cell cycle G0/G1 phase arrest (Fig. 4C and D; P<0.001) and apoptosis (Fig. 4E and F; P<0.001) when compared with si-NC transfection. Similarly, the miR-4458-induced cell cycle G0/G1 phase arrest (Fig. 4C and D, $\mathrm{P}<0.01$ ) and apoptosis (Fig. 4E and F; $\mathrm{P}<0.001$ ) was significantly enhanced when IGF1R was knocked down when compared with miR-4458 mimics transfection alone. Taken together, these results indicated that IGF1R may be a downstream target of miR-4458 in HDECs.

\section{Discussion}

The present study demonstrated that the increased expression of miR-4458 decreased proliferation and induced G0/G1 cell cycle arrest and apoptosis in HDECs, whereas transfection of miR-4458 mimics had the opposite effect. It was additionally revealed that miR-4458 mediated the repression of its target gene, IGF1R. In particular, IGF1R knockdown was demonstrated to imitate the function of endogenous miR-4458 overexpression.

Numerous miRNAs have been demonstrated to serve important roles in the development and maintenance of normal cellular functions and the dysregulated expression of miRNAs is associated with the initiation and progression of a number of different types of malignancy (28). Previous research has revealed that miR-4458 was involved in the regulation of glycolysis and lactate production in colon cancer cells by targeting hexokinase 2 (15). The suppression of cell proliferation via miR-4458 overexpression was demonstrated in HCC cells, indicating a novel tumor suppressor function of miR-4458 in HCC (14). Overexpression of miR-4458 arrested non-small-cell lung cancer A549 and H460 cells at G0/G1 stage and suppressed cell proliferation by inhibiting cyclin D1 (29). However, to the best of our knowledge, no studies have determined the effect of miR-4458 on the behavior of cellular biology in HA. In the present study, miR-4458 mimics decreased the proliferation of HDECs, induced G0/G1 phase arrest and induced apoptosis. These results demonstrated that miR-4458 exhibited an anti-proliferative and pro-apoptotic effect on HDECs.

It has been hypothesized that each miRNA has the potential to regulate a very large number (10-100) of genes by binding to specific elements in the 3'UTR of their target mRNAs (30). In the present study, IGF1R regulation by miR-4458 was demonstrated in vitro in HDECs with the use of luciferase reporter assays.

IGF1R is amplified in various types of tumors and mediates tumor transformation and malignant cell apoptosis (31). It has been demonstrated that the diminished activation of the IGF1R signaling pathway when IGF1R is downregulated, or in the presence of IGF1R-specific inhibitor picropodophyllin, significantly reduced the proliferation of cultured mouse spermatogonial stem cells by arresting cells at G2/M (32). Additionally, there is a crosstalk between the IGF1R signaling pathway and other signaling components involved in cell growth and survival (33). IGF-1R inhibitor treatment has demonstrated a notable anti-proliferative and pro-apoptotic effect, as well as G0/G1 cell cycle arrest in MDA-MB-231 cells (34). Another study revealed that the inactivation of the IGF1/IGF1R-PI3K/Akt pathway when treated with formononetin was associated with G0/G1 phase arrest in breast cancer cells (35). Mechanistically, PI3K/Akt and the Raf/MEK/ERK signaling pathways are implicated in IGF1R-mediated cell cycle distribution and protect against apoptosis in hematopoietic cells (36). Additionally, a number of growth factors and receptors, including vascular endothelial growth factor and epidermal growth factor receptor can interfere with IGF1R signaling and are considered as the key functional elements in cellular viability, cell cycle progression and apoptosis $(31,37)$. In the present study, IGF1R expression knockdown resulted in a decrease in HDEC proliferation by preventing cell cycle progression. Apoptosis analysis revealed that miR-4458 exhibited a pro-apoptotic effect in HDECs, at least in part through the direct suppression of IGF1R. However, further studies are required to determine the underlying molecular mechanisms by which IGF1R exerts its effects in HA.

In summary, the results of the present study demonstrated that miR-4458 decreased proliferation and induced apoptosis in HDECs by targeting IGF1R. The tumor suppressive effects of miR-4458 in HA may serve as a basis for the exploration of new potential therapeutic strategies.

\section{Acknowledgements}

Not applicable.

\section{Funding}

No funding was received.

\section{Availability of data and materials}

The datasets used and/or analyzed during the present study are available from the author on reasonable request.

\section{Authors' contributions}

XL designed the study. MW, YT and GH performed the experiments. CY and KY analyzed the data and wrote the manuscript. All authors read and approved the final manuscript.

\section{Ethics approval and consent to participate}

Not applicable.

\section{Patient consent for publication}

Not applicable. 


\section{Competing interests}

The authors declare that they have no competing interests.

\section{References}

1. Spence-Shishido AA, Good WV, Baselga E and Frieden IJ: Hemangiomas and the eye. Clin Dermatol 33: 170-182, 2015.

2. Phillips JD, Zhang H, Wei T and Richter GT: Expression of $\beta$-adrenergic receptor subtypes in proliferative, involuted, and propranolol-responsive infantile hemangiomas. JAMA Facial Plast Surg 19: 102-107, 2017.

3. Janmohamed SR, Madern GC, de Laat PC and Oranje AP: Educational paper: Pathogenesis of infantile haemangioma, an update 2014 (part I). Eur J Pediatr 174: 97-103, 2015.

4. Nakayama H, Huang L, Kelly RP, Oudenaarden CR, Dagher A, Hofmann NA, Moses MA, Bischoff J and Klagsbrun M: Infantile hemangioma-derived stem cells and endothelial cells are inhibited by class 3 semaphorins. Biochem Biophys Res Commun 464: $126-132,2015$.

5. Itinteang T, Davis PF and Tan ST: Infantile hemangiomas exhibit neural crest and pericyte markers. Ann Plast Surg 74: 383, 2015.

6. Acunzo M, Romano G, Wernicke D and Croce CM: MicroRNA and cancer-a brief overview. Adv Biol Regul 57: 1-9, 2015.

7. Koshizuka K, Nohata N, Hanazawa T, Kikkawa N, Arai T, Okato A, Fukumoto I, Katada K, Okamoto Y and Seki N: Deep sequencing-based microRNA expression signatures in head and neck squamous cell carcinoma: Dual strands of pre-miR-150 as antitumor miRNAs. Oncotarget 8: 30288-30304, 2017.

8. Hayes J, Peruzzi PP and Lawler S: MicroRNAs in cancer: Biomarkers, functions and therapy. Trends Mol Med 20: 460-469, 2014.

9. Biswas A, Pan X, Meyer M, Khanna S, Roy S, Pearson G, Kirschner R, Witman P, Faith EF, Sen CK and Gordillo GM: Urinary excretion of MicroRNA-126 is a biomarker for hemangioma proliferation. Plast Reconstr Surg 139: 1277e-1284e, 2017.

10. Fei Z, Qiu M, Qi X, Dai Y, Wang S, Quan Z, Liu Y and Ou J: MicroRNA-424 suppresses the proliferation of hemangioma-derived endothelial cells by targeting VEGFR-2. Mol Med Rep 18: 4065-4071, 2018.

11. Huang C, Huang J, Ma P and Yu G: microRNA-143 acts as a suppressor of hemangioma growth by targeting Bcl-2. Gene 628: 211-217, 2017.

12. Mong EF, Akat KM, Canfield J, Lockhart J, VanWye J, Matar A, Tsibris JCM, Wu JK, Tuschl T and Totary-Jain H: Modulation of LIN28B/Let-7 signaling by propranolol contributes to infantile hemangioma involution. Arterioscler Thromb Vasc Biol 38: 1321-1332, 2018.

13. Liu CH,Lv DS,Li M,Sun G,Zhang XF and Bai Y:MicroRNA-4458 suppresses the proliferation of human lung cancer cells in vitro by directly targeting Lin28B. Acta Pharmacol Sin 38: 1297-1304, 2017.

14. Tang D, Sun B, Yu H, Yang Z and Zhu L: Tumor-suppressing effect of miR-4458 on human hepatocellular carcinoma. Cell Physiol Biochem 35: 1797-1807, 2015 .

15. Qin Y, Cheng C, Lu H and Wang Y: miR-4458 suppresses glycolysis and lactate production by directly targeting hexokinase2 in colon cancer cells. Biochem Biophys Res Commun 469: 37-43, 2016.

16. Cai W, Sakaguchi M, Kleinridders A, Gonzalez-Del Pino G, Dreyfuss JM, O'Neill BT, Ramirez AK, Pan H, Winnay JN, Boucher J, et al: Domain-dependent effects of insulin and IGF-1 receptors on signalling and gene expression. Nat Commun 8: 14892, 2017.

17. Cannarella R, Mattina T, Condorelli RA, Mongioì LM, Pandini G, La Vignera $S$ and Calogero AE: Chromosome 15 structural abnormalities: Effect on IGF1R gene expression and function. Endocr Connect 6: 528-539, 2017.

18. Taliaferro-Smith LT, Oberlick E, Liu T, McGlothen T, Alcaide T, Tobin R, Donnelly S, Commander R, Kline E, Nagaraju GP, et al: FAK activation is required for IGF1R-mediated regulation of EMT, migration, and invasion in mesenchymal triple negative breast cancer cells. Oncotarget 6: 4757-4772, 2014.

19. Ball MW, Bezerra SM, Chaux A, Faraj SF, Gonzalez-Roibon N, Munari E, Sharma R, Bivalacqua TJ, Netto GJ and Burnett AL: Overexpression of insulin-like growth factor-1 receptor is associated with penile cancer progression. Urology 92: 51-56, 2016.
20. Qian Y, Teng Y, Li Y, Lin X, Guan M, Li Y, Cao X and Gao Y: miR-143-3p suppresses the progression of nasal squamous cell carcinoma by targeting Bcl-2 and IGF1R. Biochem Biophys Res Commun 518: 492-499, 2019.

21. Zaanan A, Calmel C, Henriques J, Svrcek M, Blons H, Desbois-Mouthon C, Merabtene F, Goumard C, Parc Y, Gayet B, et al: High IGF1R protein expression correlates with disease-free survival of patients with stage III colon cancer. Cell Oncol (Dordr): Dec 10, 2019 (Epub ahead of print). doi: 10.1007/s13402-019-00484-6.

22. Wang XH, Wu HY, Gao J, Wang XH, Gao TH and Zhang SF: IGF1R facilitates epithelial-mesenchymal transition and cancer stem cell properties in neuroblastoma via the STAT3/AKT axis. Cancer Manag Res 11: 5459-5472, 2019.

23. Ou JM, Lian WS, Qiu MK, Dai YX, Dong Q, Shen J, Dong P, Wang XF, Liu YB, Quan ZW and Fei ZW: Knockdown of IGF2R suppresses proliferation and induces apoptosis in hemangioma cells in vitro and in vivo. Int J Oncol 45: 1241-1249, 2014.

24. Liu ZQ, Fu WQ, Zhao S and Zhao X: Regulation of insulin-like growth factor 1 receptor signaling by microRNA-4458 in the development of lumbar disc degeneration. Am J Transl Res 8: 2309-2316, 2016.

25. Fu X, Zhai S and Yuan J: Interleukin-6 (IL-6) triggers the malignancy of hemangioma cells via activation of HIF-1 $\alpha /$ VEGFA signals. Eur J Pharmacol 41: 82-89, 2018.

26. Qiu MK, Wang SQ, Pan C, Wang Y, Quan ZW, Liu YB and Ou JM: ROCK inhibition as a potential therapeutic target involved in apoptosis in hemangioma. Oncol Rep 37: 2987-2993, 2017.

27. Livak KJ and Schmittgen TD: Analysis of relative gene expression data using real-time quantitative PCR and the 2(-Delta Delta C(T)) method. Methods 25: 402-408, 2001.

28. Bandres E, Bitarte N, Arias F, Agorreta J, Fortes P, Agirre X, Zarate R, Diaz-Gonzalez JA, Ramirez N, Sola JJ, et al: microRNA-451 regulates macrophage migration inhibitory factor production and proliferation of gastrointestinal cancer cells. Clin Cancer Res 15: 2281-2290, 2009.

29. Bao L, Wang L, Wei G, Wang Y, Wuyun G and Bo A: Role of microRNA-4458 in patients with non-small-cell lung cancer. Oncol Lett 12: 3958-3966, 2016

30. Hoffman Y, Bublik DR, Ugalde AP, Elkon R, Biniashvili T, Agami R, Oren M and Pilpel Y: 3'UTR shortening potentiates MicroRNA-based repression of pro-differentiation genes in proliferating human cells. PLoS Genet 12: e1005879, 2016.

31. Zakraoui O, Marcinkiewicz C, Aloui Z, Othman H, Grépin R, Haoues M, Essafi M, Srairi-Abid N, Gasmi A, Karoui H, et al: Lebein, a snake venom disintegrin, suppresses human colon cancer cells proliferation and tumor-induced angiogenesis through cell cycle arrest, apoptosis induction and inhibition of VEGF expression. Mol Carcinog 56: 18-37, 2017.

32. Wang S, Wang X, Wu Y and Han C: IGF-1R signaling is essential for the proliferation of cultured mouse spermatogonial stem cells by promoting the G2/M progression of the cell cycle. Stem Cells Dev 24: 471-483, 2015 .

33. Zhang M, Liu J, Li M, Zhang S, Lu Y, Liang Y, Zhao K and Li Y: Insulin-like growth factor $1 /$ insulin-like growth factor 1 receptor signaling protects against cell apoptosis through the PI3K/AKT pathway in glioblastoma cells. Exp Ther Med 16: 1477-1482, 2018.

34. Ayub A, Yip WK and Seow HF: Dual treatments targeting IGF-1R, PI3K, mTORC or MEK synergize to inhibit cell growth, induce apoptosis, and arrest cell cycle at G1 phase in MDA-MB-231 cell line. Biomed Pharmacother 75: 40-50, 2015.

35. Li T, Zhao X, Mo Z, Huang W, Yan H, Ling Z and Ye Y: Formononetin promotes cell cycle arrest via downregulation of Akt/Cyclin D1/CDK4 in human prostate cancer cells. Cell Physiol Biochem 34: 1351-1358, 2014.

36. Chen J, Duan Y, Zhang X, Ye Y, Ge B and Chen J: Genistein induces apoptosis by the inactivation of the IGF-1R/p-Akt signaling pathway in MCF-7 human breast cancer cells. Food Funct 6: 995-1000, 2015

37. Dai Z, Wang L, Wang X, Zhao B, Zhao W, Bhardwaj SS, Ye J, Yin Z, Zhang J and Zhao S: Oxymatrine induces cell cycle arrest and apoptosis and suppresses the invasion of human glioblastoma cells through the EGFR/PI3K/Akt/mTOR signaling pathway and STAT3. Oncol Rep 40: 867-876, 2018.

This work is licensed under a Creative Commons Attribution-NonCommercial-NoDerivatives 4.0 International (CC BY-NC-ND 4.0) License. 